\title{
O papel do Controller no Gerenciamento do Sistema de Informação contábil e na consecução das diretrizes organizacionais
}

\author{
Fábio Jorge Nascimento Ferreira ${ }^{1}$; Hesler Piedade Caffé Filho ${ }^{2}$
}

\begin{abstract}
Resumo: O objetivo precípuo deste trabalho é subsidiar informações a acadêmicos, estudantes e curiosos, dentre outros, sobre a conceituação e importância da Contabilidade Gerencial no mercado atual, tendo como seu principal agente o Controller, figura indispensável para a adequação e implementação da Diretriz Organizacional adotada, bem como na gestão do Sistema de Informação Contábil. Desenvolvido através de estudos sobre Controladoria, Contabilidade Gerencial e Controle Gerencial, evidenciando-se como um artigo de revisão, e complementado com artigos e pesquisas condizentes com a realidade da profissão, o citado trabalho preocupouse, basicamente, em realizar uma análise estrutural e bastante didática, verificando atuação, realidade e perspectiva e, num segundo momento, fomentar o interesse por tal ramo da Contabilidade, dismistificando-o e focando o pefil do profissional que, porventura, adentrar esta área.
\end{abstract}

Palavras-chave: Contabilidade Gerencial. Controller. Gerenciamento.

\section{The role of the Controller in the accounting information system management and the achievement of organizational guidelines}

\begin{abstract}
The main objective of this work is to support information to scholars, students and curious, among others, about the concept andimportance of Management Accounting in the current market, having as its main agent Controller, indispensable figure for the adequacy and implementation of the Organizational Guidelines adopted, as well as the management of the Accounting Information System. Developed Though studies on Controlling, Management Accounting and Management Control, is showing as a review article andcomplemented with articles and consistent research with the reality of the profession, the work cited was concerned basically to perform a structural analysis and rather didactic, checking performance, reality and perspective and, second, to foster interest in this branch of Accounting dismistificando it and focusing on this profile of professional, perhaps enter this area.
\end{abstract}

Keywords: Managerial Accounting . Controller. Organizational . Management.

\section{Introdução}

Evolução e dinamismo são as palavras que agora regem o nosso competitivo e capitalista mundo. As ações não são mais inertes, nem isoladas como outrora eram e é nesta consoante que a comunicação, bem como o conhecimento sistêmico agregado e aplicado, tornaram-se instrumentos, quiçá armas determinantes, para que as empresas pudessem sobressair nesta acirrada corrida acerca da lucratividade e do sucesso.

\footnotetext{
${ }^{1}$ Universidade Federal do vale do São Francisco - UNIVASF.

${ }^{2}$ Mestrado Profissional em Mestrado em Gestão de Políticas Públicas pela Universidade Federal do Recôncavo da Bahia, Brasil. Professor de Pós Graduação da Universidade Federal do Vale do São Francisco, Brasil
} 
Id on Line Revista Multidisciplinar e de Psicoloqia

Id on Line Revista Multidisciplinar e de Psicologia

A palavra comunicação pode provocar uma momentânea estranheza, entretanto, compreendemos também que a Contabilidade, tendo na figura do Contabilista um grande comunicador e gestor, é a arte da comunicação, do se fazer entender e do transmitir, através, é claro, da codificação das informações a respeito do funcionamento e continuidade duma dada empresa. O gerir informação também perpassa por tal ação e se torna bem evidente se nos remetermos ao conceito de Contabilidade pontuado por Hilário Franco (1997), conforme o qual preconiza que a Ciência em voga tem como objetivos claros:

[...] o de registrar, classificar, demonstrar, auditar e analisar todos os fenômenos que ocorrem no patrimônio das entidades, objetivando fornecer informações,nterpretações e orientações... para a tomada de decisões de seus administradores (FRANCO, 1997, p.19 grifo nosso).

Interessante citarmos que a Ciência Contábil acompanhou a supracitada evolução, pois, como ciência social que é, soube muito bem adaptar-se às novas mudanças e demandas sociais, exigindo capacitação e reformulação dos seus profissionais e de suas normas, respectivamente; ao passo que ampliou a sua gama de atuação, desmembrando-se em diversas outras áreas, tais como: Controladoria, Auditoria, Contabilidade Gerencial, Contabilidade Financeira dentre outras, formando, assim, um arcabouço contábil completo.

Porém, a área de atuação da Contabilidade é infinita, não se restringindo ao que foi dito somente, e, partindo da premissa conceitual de que todo Contabilista é um gerador e gestor de informações, cabe também refletirmos como se dá a sua participação na condução do Sistema de Informações Contábeis, assim como a sua influência na implementação e adequação da Diretriz Organizacional.

Doravante, com o objetivo de ser didático, procuraremos, de forma lógica e sistemática, elencar os conceitos necessários para que se possa obter um entendimento aceitável sobre a Contabilidade Gerencial, visto que este é o foco do trabalho em questão.

\section{Sobre a Contabilidade Geral: Objetivo, Função e Objeto de Estudo}

É óbvio que, ao discorrermos sobre a Contabilidade Geral, devemos procurar os elementos basilares para poder fundamentá-la de forma consistente, inclusive verificando, na medida do possível, as possíveis diferenciações e peculiaridades que são atinentes a cada um dos seus ramos.

Segundo Hilário Franco (1997, p. 22), “a Contabilidade é a ciência que estuda e controla o patrimônio das entidades econômico-administrativas, registrando todos os fatos nele ocorridos, para demonstrar e interpretar, a qualquer momento, seu estado e suas variações”. Assim sendo, suas 
Id on Line Revista Multidisciplinar e de Psicoloqia

Id on Line Revista Multidisciplinar e de Psicologia

funções compreendem: o registro, a classificação, a demonstração, a auditoria e a análise de todos os fenômenos que ocorrem no âmbito patrimonial das entidades, objetivando tão somente fornecer informações, interpretações e orientações aos seus administradores, para as conseguintes tomadas de decisões.

Mas, o que se entende por patrimônio? E por entidade? Patrimônio nada mais é do que o conjunto de bens, obrigações e direitos atrelados a uma entidade, sendo considerado o objeto de estudo da Contabilidade. Por sua vez, conceitua-se entidade como "a célula social onde o homem desenvolve atividades para a satisfação de suas necessidades" (SÁ, 1997, p. 99).

Resumidamente, pode-se concluir que a Contabilidade é a ciência que estuda os fenômenos patrimoniais, utilizando-se de técnicas específicas - dentre elas, podemos citar a escrituração, demonstração e a auditoria - para assegurar o controle da azienda ${ }^{48}$, através da geração e fornecimento de informações necessárias às tomadas de decisões pelos gestores.

É nesse tocante que se começa a vislumbrar como se verdadeiramente dá o tratamento dos fatos ocorridos no patrimônio, quais ferramentas, quais profissionais, quais especificações são precisas para, através deste montante de fatos e dados, transformá-lo em informações necessárias à gestão organizacional.

\section{Ramificações da Contabilidade Geral}

Definidos os objetivos, funções e objeto da Contabilidade, conjugaremos agora algumas abordagens acerca da Contabilidade Gerencial e da Contabilidade Financeira, a fim de dirimirmos possíveis dúvidas a respeito de suas peculiaridades e conceituações e consequentemente propiciar o entendimento e desenvolvimento deste trabalho científico.

Para o imediato entendimento sobre a diferenciação dos dois ramos supracitados, utilizaremos o artifício mencionado por Frezatti (2007, p. 9-11 apud HANSEN; MOWEN, 1997, p. 37), para quem o fator diferencial se dará somente pelo público-alvo da informação. O que se quer dizer é o seguinte: a Contabilidade Gerencial, assim como a Contabilidade Financeira, têm, como objetivo principal, fornecer informações a partir de análises, mensurações e interpretações dos fatos ocorridos no âmbito patrimonial, porém o elemento que as diferencia é o tratamento e direcionamento da informação. O público-alvo da Contabilidade Gerencial é o usuário interno, tomemos como exemplo os gerentes, administradores e sócios da empresa e, em contrapartida, a Contabilidade Financeira visa fornecer os mesmos subsídios informativos, agora, porém, para o público externo, que podemos entender como: Bancos, governo, investidores, entre outros.

${ }^{48}$ Entendemos azienda por patrimônio. 
Ratificando o que foi dito acima, Padoveze (2000, p. 3) precisamente define os elementos peculiares de cada um dos ramos contábeis:

[...] A Contabilidade Gerencial é relacionada com o fornecimento de informações para os administradores - isto é, aqueles que estão dentro da organização e que são responsáveis pela direção e controle de suas operações. A Contabilidade Financeira pode ser contrastada com a Contabilidade Financeira, que é relacionada com o fornecimento de informações para os acionistas, credores e outros que estão fora da organização. (PADOVEZE, 2000, p. 3).

Tomemos como base a tabela sugerida pelo próprio Padoveze (2000, p. 31-32) que, através da comparação de alguns elementos, consegue distinguir bem o que cada um dos ramos preconiza. Logo abaixo,

Quadro 1: Comparação entre a Contabilidade Gerencial e a Contabilidade Financeira

\begin{tabular}{|c|c|c|}
\hline FATO & CONTABILIDADE FINANCEIRA & $\begin{array}{l}\text { CONTABILIDADE } \\
\text { GERENCIAL }\end{array}$ \\
\hline Usuários dos relatórios & Externos e Internos & Internos \\
\hline Objetivos dos relatórios & $\begin{array}{l}\text { Facilitar a análise financeira para as } \\
\text { necessidades dos usuários externos }\end{array}$ & $\begin{array}{l}\text { Facilitar o planejamento, controle, } \\
\text { avaliação de desempenho e tomada } \\
\text { de decisão internamente }\end{array}$ \\
\hline Forma dos relatórios & $\begin{array}{l}\text { Balanço Patrimonial, Demonstração } \\
\text { dos Resultados, Demonstração das } \\
\text { Origens e Aplicações, Demonstrações } \\
\text { das Mutações do Patrimônio Líquido }\end{array}$ & $\begin{array}{l}\text { Orçamentos, contabilidade por } \\
\text { responsabilidade, relatórios de } \\
\text { desempenho, relatórios de custo, } \\
\text { relatórios não rotineiros para } \\
\text { facilitar a tomada de decisão }\end{array}$ \\
\hline Freqüência dos relatórios & Anual, trimestral, e ocasionalmente & $\begin{array}{l}\text { Quando necessário pela } \\
\text { administração }\end{array}$ \\
\hline Arcabouço teórico e técnico & Ciência Contábil & \begin{tabular}{|l|} 
Utilização pesada de outras \\
disciplinas, como economia. \\
Finanças, estatística, pesquisa \\
operacional e comportamento \\
organizacional
\end{tabular} \\
\hline $\begin{array}{l}\text { Características da informação } \\
\text { fornecida }\end{array}$ & $\begin{array}{l}\text { Deve ser objetiva (sem viés), } \\
\text { verificável, relevante e a tempo }\end{array}$ & $\begin{array}{l}\text { Deve ser relevante e a tempo, } \\
\text { podendo ser subjetiva, possuindo } \\
\text { menos verificabilidade e menos } \\
\text { precisão }\end{array}$ \\
\hline Perspectiva dos relatórios & Orientação histórica & $\begin{array}{l}\text { Orientada para o futuro para } \\
\text { facilitar o planejamento, controle e } \\
\text { avaliação antes do fato }\end{array}$ \\
\hline
\end{tabular}

Fonte: Adaptado de PADOVEZE, 2000, p. 31-32. 
Id on Line Revista Multidisciplinar e de Psicoloqia

Id on Line Revista Multidisciplinar e de Psicologia

\section{Desmitificando a Contabilidade Gerencial}

Ao identificarmos as peculiaridades atinentes à Contabildade Fianceira e à Contabilidade Gerencial, começam - mesmo sendo esparsas - a aparecer algumas idéias daquilo com que, de fato, a Contabilidade Gerencial lida: sua conceituação, seus elementos e o que a torna tão importante no âmbito organizacional e estratégico das empresas.

Além disso, surge uma inquietação e curiosidade a respeito dos seus principais agentes, seus objetivos e instrumentos.

Crepaldi (2004, p. 20) diz que:

[...] a Contabilidade Gerencial é o ramo da Contabilidade que tem por objetivo fornecer instrumentos aos administradores de empresas que os auxiliem em suas funções gerenciais. É voltada para a melhor utilização dos recursos econômicos da empresa, através de um adequado controle de insumos efetuado por um sistema de informação gerencial. (CREPALDI, 2004, p. 20).

Entretanto, para que a conceituação se torne completa, corroboraremos aqui com o pensamento de Padoveze (2000, p. 32), segundo o qual a "Contabilidade Gerencial é uma disciplina integradora". Diferentemente da Administração Financeira ou da Contabilidade de Custos, a Contabilidade Gerencial se realiza com a integração de todos esses sub-setores, utilizando-se dos recursos de ambos, a fim de que se torne o mais fidedigno e preciso instrumento da administração, na medida em que for solicitado, é claro. Entende-se que o seu caráter integrador é o diferencial e, num dado momento, inevitavelmente, surgirá a seguinte pergunta: para que este ramo se concretize, devemos considerá-la como uma técnica específica ou como uma ação?

Tão logo, para que se sane tal dúvida, basta-nos ater ao conceito integrador abordado por esta Contabilidade, pois, na medida em que se agregam os instrumentos utilizados e exercitados por outros ramos, não há uma necessidade de tecnicidade, e sim, de uma intencionalidade, de uma ação proposta pela administração que venha a ajudá-la, a contribuir para a tomada da melhor decisão.

Não obstante, temos ciência de que alguns autores, tais como Padoveze, Frezatti e outros consideram que a Contabilidade Gerencial é, sobretudo, uma ação administrativa, que engloba em seu bojo, diversos temas relacionados aos processos administrativos tão quanto aos processos integrados de tomada de decisões.

\section{O Papel do Controller no Gerenciamento das Informações}

Não há como termos a plena compreensão teórica e prática da Contabilidade Gerencial sem que saibamos a definição de Controladoria, Controller e Controle Interno. Ao conhecermos tais 
Id on Line Revista Multidisciplinar e de Psicologia

Id on Line Revista Multidisciplinar e de Psicologia

conceitos, teremos noção de quão importantes são para o contexto organizacional e como influenciam na consecução da Diretriz Organizacional.

Conforme Ricardino (2005, p.167), controladoria é "um órgão dentro da empresa que tem como objetivo a adoção de técnicas que fornecem informações precisas, colaborando para o alcance das metas [...]", além do mais, o mesmo autor escreve, mais tarde, que "[...] essa função precisava ser realizada por alguém capaz de fazer das informações contábeis um instrumento de controle e apoio à decisão […]".

De acordo com o parágrafo acima, entendemos o papel da Controladoria na eficácia do processo de gestão da empresa, sendo esta executada e coordenada pelo Controller - "o alguém capaz" - a partir da manipulação dos controles internos, relatórios, demonstrativos e outros.

Contudo, há de se ressaltar que a Controladoria toma forma a partir do papel do Controller, que firma-se como o:

[...] responsável pelo projeto, elaboração, implementação do sistema integrado de informações operacionais, financeiras e contábeis de determinada entidade... tendo papel preponderante no auxílio e no emprego das melhores práticas de controle... bem como suprindo a alta administração com ferramentas de análise e controle gerencial, possibilitando o alcance das metas organizacionais estabelecidas. (GARCIA, 2010, p. 2).

Não obstante, podemos encontrar o termo Contador Gerencial ou Gerente Contábil , que nada mais são do que outras nomenclaturas empregadas ao Controller.

Por ora, para que completemos o raciocínio, coadunamos que o controle interno compreende o plano de organização e o conjunto coordenado de métodos e medidas, adotados pela empresa, para proteger seu patrimônio, verificar a exatidão e a fidedignidade de seus dados contabilísticos, promover a eficiência operacional e encorajar a adesão à política traçada pela administração (LAMPEAO, 2010).

A partir do que foi exposto, pecebemos que a Contabilidade Gerencial se concretiza através da tríade constituída pela Controladoria, Controller e Sistema de Informação Contábil, todavia ainda há uma pendência, que é deveras determinante para o entendimento do trabalho. Enfatizamos, também, que o Controller é o detentor das principais informações ocorridas no ambiente patrmonial, e só o mesmo teria o cabedal teoríco e prático a ponto de codificá-las e redirecioná-las para uma melhor aplicação das decisões organizacionais.

Cabe a nós pensarmos: o que de fato seria o Sistema de Informação Contábil e como ocorre essa interação?

\section{A Contabilidade Gerencial e o Sistema de Informação Contábil}

Segundo o Francisco S. Borba (2004, p. 1293), "sistema" significa o conjunto das partes ou dos elementos de um todo, coordenados entre si, que funciona como estrutura organizada. Porém, ao 
Id on Line Revista Multidisciplinar e de Psicologia

Id on Line Revista Multidisciplinar e de Psicologia

lidarmos com um tipo específico de sistema, o de Informação, elencaremos Padoveze (2000), que o define como:

[...] um conjunto de recursos humanos, materiais, tecnológicos e financeiros agregados segundo uma sequência lógica, para o processamento dos dados e tradução em informações, para com o seu produto, permitir às organizações o cumprimento de seus objetivos principais. (PADOVEZE, 2000, p. 42).

Dentre as suas ramificações, os Sistemas de Informação podem ser classificados em duas esferas: o de Apoio às Operações e os de Apoio à Gestão. Dentre essas duas, a que tem grande valia para a Contabilidade é a segunda, pois, ao se preocupar e lidar com as informações necessárias para a gestão econômico-financeira, estará interiamente contribuindo para a sobrevivência e continuidade da empresa.

Logo, nesse ponto, poderíamos compreender a Contabilidade como um amplo Sistema de Informação, mas, para que sejamos didáticos e sistemáticos, traduziremos o Sistema de Informação Contábil como um Sistema de Apoio à Gestão que tem como premissa o fornecimento de apoio informacional a fim de auxiliar a tomada de decisões gerenciais, em conjunto com os Sistemas de Controladoria e Finanças.

De posse de tantos sistemas, como as empresas fazem para interligá-los e torná-los eficientes dentro de suas especificidades e do que a empresa tem como meta, os tornando úteis e aplicáveis?

A interação entre os sistemas supracitados, dar-se-á através de outros dois sistemas, agindo como se fossem codificadores, e servindo de base para o refinamento e tratamento das informações coletadas. Primeiramente, através do Sistema de Informação de Apoio à Decisão; que se utiliza dos bancos de dados dos sistemas operacionais e gestores; e num segundo momento, do Sistema Integrado de Gestão Empresarial, que tem como fundamental objetivo a consolidação e junção de todas as informações necessárias para o gerenciamento do sistema empresarial.

\section{Perfil Profissional e Pessoal do Controller}

É preciso fazer aqui um adendo, pois, ao discorrermos sobre sua conceituação, função e relevância na gestão de uma entidade, inevitavelmente, surgem questionamentos a respeito de postura, seja ela profissional ou pessoal, bem como a capacitação e a qualificação.

Em face da amplitude de atividades atreladas ao Controller, da sua necessidade em ter uma visão macro e da sua capacidade de gerenciamento e direcionamento das informações, podemos, brevemente, dizer que tal profissional deve ser o mais gabaritado possível, o que significa obter e utilizar noções de diversas outras áreas do conhecimento, tais como Economia, Direito, 
Id on Line Revista Multidisciplinar e de Psicologia

Id on Line Revista Multidisciplinar e de Psicologia

Administração, além do mais, de estar concatenando com o negócio em si, com as tecnologias, com a globalização, com a Diretriz Organizacional estabelecida e ser detentor de uma ótima percepção de planejamento.

Com o intuito de identificarmos e traçarmos o perfil profissional esperado para o Contador Gerencial, entende-se Controller, ROCHA e outros (2009, p. 37) pontuam:

[...] Um Controller deve possuir conhecimentos de gestão, para que possa compreender e participar do processo de planejamento e controle. O domínio de conceitos de contabilidade, despesas e custos, tributos, tecnologia de informação etc. é fundamental. Além disso, noções básicas e fundamentais de economia, sociologia, psicologia e estatística também ajudam no desempenho das suas funções. (ROCHA, 2009, p. 37)

É válido pontuar que não há uma obrigatoriedade para que o Controller tenha formação acadêmica em Ciências Contábeis, pois, pesquisas diversas constataram que muitos desses profissionais são formados em outras áreas do conhecimento, tais como: Administração, Economia e, por que não, Engenharia; entretanto, é condição sine qua non que os mesmos tenham um forte embasamento de conhecimentos contábeis.

Dando continuidade, não teríamos como dissociar o Perfil Profissional do Perfil Pessoal, e para tanto, as prerrogativas necessárias para a formação deste perfil já foram, conotativamente, delineadas.

Afirma-se isto em virtude de que o profissional que detém tamanho conhecimento, deve ter no mínimo, um bom raciocínio lógico e sistêmico, equilibrio emocional, alto nível de energia e liderança, ótima comunicação, senso dinâmico e detalhista, dentres outras habilidades e competências.

Rocha (2009, p. 38) enfatiza que tal profissional deve ter postura proativa e saber olhar para o futuro. Perspicácia, iniciativa e aptidão são características triviais e concernentes ao Contador Gerencial, que, em muitos dos casos, a fim de mitigar a postura de "carrasco", por se encontrar na posição de fiscalizador, deve atuar como um mediador, uma facilitador dos processos, um assessor nos assuntos de sua competência, desde que os mesmos estejam indo de encontro com os destinos da organização.

Da mesma forma, a conduta ilibada, calcada nos ditames éticos, técnicos e morais, deve ser a sua marca, tornando-se uma referência profissional e sinônimo de integridade, imparcialidade e idoneidade, em detrimento da tamanha responsabilidade e importância que perpassam pela a sua pessoa.

Por fim, para total compreensão do Perfil Pessoal, faz-se válido frisar o que Rocha (2009, p. 38) cita: 
[...] O profissional responsável pela Controladoria deve ter espírito de liderança, ser capaz de motivar seus subordinados, saber e gostar de trabalhar em equipe, saber comunicar-se tanto oralmente como por escrito e estar atualizado não só com o que acontece na sua empresa como também com o que ocorre no mundo e cultivar a capacidade de adaptar-se às mudanças. (ROCHA, 2009, p. 38)

\section{Controller e a Consecução da Diretriz Organizacional}

As Diretrizes Organizacionais são os caminhos firmemente estabelecidos que determinarão e guiarão os passos da empresa, contribuindo para o pleno futuro do negócio, quando bem elaboradas.

As diretrizes são constituídas pelo tripé missão, visão e objetivos organizacionais. Sua função é indicar a meta organizacional que propiciará melhor aproveitamento dos recursos da empresa, antenadas as suas vantagens e desvantagens. E, nesse ponto, o papel do Controller, torna-se imprescindível, pois é o agente capaz de identificar tais pontos e manipular os meios a fim de ratificálos ou retificá-los.

Compreendemos como missão organizacional o motivo existencial da empresa, a qual deverá arrolar e especificar quem são os seus clientes; seus produtos ou serviços; seus valores e cultura organizacionais. Nesse tocante, é necessária a presença, novamente, da figura do Contoller, pois a sua razão de existir na empresa é fundida à razão de ser da empresa. O Contador Gerencial coexiste para que a empresa possa desenvolver-se de forma plena, assegurando-lhe os melhores meios, recursos, informações e decisões.

Atrelamos ao seu papel também, a ampla comunicação e pulverização desta missão, pois aceita-se o Controller como um mediador/comunicador dos focos almejados pela empresa, agregando todos à sua volta, em prol, unicamente, do melhor a todos aqueles que estão vinculados à empresa.

Logo, as Diretrizes são o que a empresa espera, ou seja, seus objetivos, pois, delimitando-os, a empresa direcionará eficientemente os seus empenhos.

De acordo com o autor Samuel Certo (1993, p. 47) "os objetivos fornecem o fundamento para o planejamento, organização, motivação e controle. Sem objetivos e sua comunicação efetiva, a empresa pode tomar qualquer direção". Esses objetivos devem ser bem elaborados sob pena de comprometer todo o processo do planejamento já iniciado.

Traçando-se os objetivos organizacionais, os mesmos servirão de base para a tomada de decisões, remetendo-nos justamente à figura do Controller, que desempenha fundamental papel no processo de tomada de decisões, como outrora vimos.

Decerto que, ao se ter ciência das diretrizes organizacionais, o Controller, comprometido com a implementação destas diretrizes, será o profissional responsável e capacitado por essa operacionalização. 
Id on Line Revista Multidisciplinar e de Psicologia

Id on Line Revista Multidisciplinar e de Psicologia

\section{Conclusão}

É mister da Ciência Contábil a arte de prover informações. Nesse diapasão, mesmo que pretendamos aglutinar conceituações de outros pensadores, em algum momento, o ponto de convergência inevitavelmente será o de fornecer informações visando a tomada de decisões.

Se estimularmos essa convergência e observarmos a evolução da Ciência Contábil como um todo, claramente, preceberemos que a mesma se encontra no seu ápice, no que tange à normatização, técnicas e, principalmente, relevância na sobrevivência de uma entidade econômico-administrativa.

O Contador não é mais um mero pagador, sua contribuição está muito mais além, atuando como um médico, cujo paciente é a empresa, cabendo-lhe todo o tipo de cuidado, a fim de propiciarlhe o melhor atendimento, identificando as fraquezas, participando da consecução das diretrizes por ela estabelecida e, sobretudo, auxiliar, no que for preciso para a escolha da decisão mais acertada.

Ao longo do trabalho, o leitor depararou-se com diversos conceitos, a fim, tão somente, de estabelecer uma base sólida para o aceitável entendimento do Contador, na figura do Controller, ou seja, o agente capaz de manipular as informações atinentes ao Sistema de Informação Contábil e consequentemente, da importância deste profissional na sobrevivência da empresa e da execução e operacionalização das diretrizes por ela estabelecida.

Reinteirando, a Contabilidade é uma Ciência de infinita aplicação, cabendo a nós profissionais uma visão macro e orgânica, seja da sua empresa, seja das pessoas e do mundo, não se deixando levar pela inércia ou pela acomodação, visto que as nossas relações estão cada vez mais instantânes e dinâmicas, forçando-nos a perspicácia e atenção.

Por fim, espera-se que o referido trabalho sirva como um convite, para que, além de despertar outras pesquisas sobre tal seara, incentive, especificamente, os profissionais de Contabilidade a atuarem neste sentido, tendo em vista a carência do mercado por profissionais que prestem tal serviço. Atualização e capacitação são as palavras-chave da nova ordem mundial.

\section{Referências}

BORBA, Francisco S. Dicionário UNESP do Português Contemporâneo. São Paulo: Unesp, 2004.

CERTO, Samuel. Administração Estratégica: Planejamento e Implantação da Estratégica. São Paulo: Makron Books, 1993

CREPALDI, Sílvio Aparecido. Contabilidade Gerencial - Teoria e Prática. 3. ed. São Paulo: Atlas, 2004. 
Id on Line Revista Multidisciplinar e de Psicoloqia

Id on Line Revista Multidisciplinar e de Psicologia

FRANCO, Hilário. Contabilidade Geral. 23. ed. São Paulo: Atlas, 1997.

FREZATTI, Fábio; AGUIAR, Andson B.; GUERREIRO, Reinaldo. Diferenciações entre a Contabilidade Financeira e a Contabilidade Gerencial: uma pesquisa empírica a partir de pesquisadores de vários países. Revista de Contabilidade Financeira. USP. São Paulo, maio-ago, 2007, p. 9-22.

GARCIA, Alexandre Sanches. Introdução à Controladoria - Instrumentos Básicos de Controle de Gestão das Empresas. São Paulo: Atlas, 2010.

GIL, Antônio Carlos. Como Elaborar Projetos de Pesquisa. 2. ed. São Paulo: Atlas, 1991.

IUDÍBICUS, Sérgio de. Contabilidade Gerencial. 5. ed. São Paulo: Atlas, 1995.

JUNQUEIRA, Emanuel; NASCIMENTO, Artur R.; ROCHA, Wellington; FREZATTI, Fábio. Controle Gerencial - Uma Abordagem da Contabilidade Gerencial no Contexto Econômico, Comportamental e Sociológico. São Paulo: Atlas, 2009.

LAMPEÃO, Odibar. O que é o Controle Interno? Disponível em: <http://ojpeao.blogs.sapo.mz/9881.html>. Acesso em: 22 Jun. 2010.

PADOVEZZE, Clóvis Luís. Contabilidade Gerencial - Um Enfoque em Sistema de Informação Contábil. 3. ed. São Paulo: Atlas, 2000.

RICARDINO, Álvaro. Contabilidade Gerencial e Societária: Origens e Desenvolvimento. 1. ed. São Paulo: Saraiva, 2005.

SÁ, Antônio Lopes de. História Geral e das Doutrinas da Contabilidade. São Paulo: Atlas, 1997.

SILVA, Antônio Carlos Ribeiro da. Metodologia da Pesquisa Aplicada à Contabilidade. 2. ed. São Paulo: Atlas, 2006.

WARREN, Carls; REEVE, James; FESS, Philip. Contabilidade Gerencial. São Paulo: Pioneira Thomson Learning, 2001.

Como citar este artigo (Formato ABNT):

FERREIRA, F.J.N.; CAFÉ FILHO, H.P. O papel do Controller no Gerenciamento do Sistema de informação Contábil e na Consecução das Diretrizes Organizacionais. Id on Line Revista Multidisciplinar e de Psicologia, Junho de 2016, vol.10, n.30, Supl 2, p. 346-356. ISSN 1981-1179.

Recebido: $10 / 05 / 2016$

Aceito: 19/05/2016 